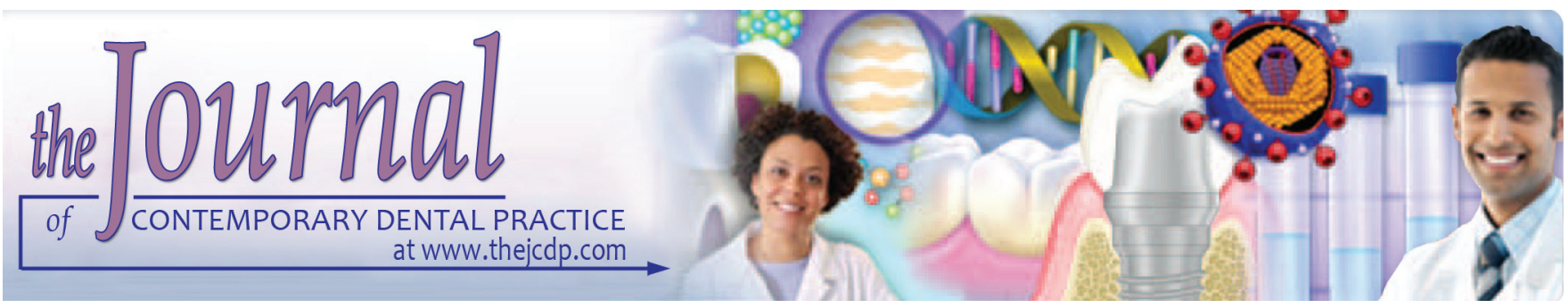

\title{
Evaluation of Apical Vapor Lock Formation and comparative Evaluation of its Elimination using Three different Techniques: An in vitro Study
}

\author{
${ }^{1}$ Anand Agarwal, ${ }^{2}$ Rahul B Deore, ${ }^{3}$ Kavitarani Rudagi, ${ }^{4}$ Zinnie Nanda, ${ }^{5}$ Mirza Osman Baig, ${ }^{6}$ Md Adil Fareez
}

\begin{abstract}
Aim: The aim of this study was (i) to evaluate the formation of air bubbles in the apical region of root canal (apical vapor lock) during syringe irrigation, using cone beam computed tomography (CBCT) and (ii) comparative evaluation of the elimination of an established vapor lock by EndoActivator, ultrasonics, and manual dynamic agitation (MDA), using CBCT.
\end{abstract}

Materials and methods: A total of 60 extracted human singlerooted teeth were equally divided into three groups of 20 teeth each. The samples were decoronated $17 \mathrm{~mm}$ from the apex, cleaned, and shaped to size F4 Protaper using 3\% sodium hypochlorite. Samples were irrigated with $3 \%$ sodium hypochlorite + cesium chloride radiopaque dye, and preoperative CBCT images were obtained. After formation of apical vapor lock in the scanned teeth, EndoActivator (group I), passive ultrasonic irrigation (group II), and MDA with K-file (group III) were performed and the teeth were again placed in CBCT scanner and results analyzed using the chi-square test.

Results: The apical vapor lock was formed in all the samples. Out of the 20 teeth in each group, the apical vapor lock was eliminated in 18 samples of EndoActivator group (90\%), 16 samples of ultrasonic group ( $80 \%)$, while it was eliminated in 10 samples by MDA $(50 \%)$.

Conclusion: It is concluded that (1) apical vapor lock is consistently formed during endodontic irrigation in closed canal systems and (2) sonic activation performs better than the ultrasonics and MDA in eliminating the apical vapor lock, with statistically significant difference between all the three groups $(p<0.05)$.

Clinical significance: The results suggest that the apical vapor lock (dead water zone) is consistently formed during routine

\footnotetext{
${ }^{1-4}$ Department of Conservative Dentistry and Endodontics A.C.P.M. Dental College, Dhule, Maharashtra, India

${ }^{5,6}$ Department of Conservative Dentistry and Endodontics, HKE Society's SN Dental College, Gulbarga, Bengaluru, Karnataka India

Corresponding Author: Kavitarani Rudagi, Department of Conservative Dentistry and Endodontics, A.C.P.M. Dental College Dhule, Maharashtra, India, Phone: +919673390777, e-mail: kavita.rudagi@gmail.com
}

endodontic irrigation which impedes irrigant penetration till the working length, thereby leading to inefficient debridement. Hence, to eliminate this vapor lock, techniques, such as sonics or ultrasonics should be used along with the irrigant after shaping and cleaning of the root canal.

Keywords: Apical vapor lock, EndoActivator, Manual dynamic agitation, Passive ultrasonic irrigation.

How to cite this article: Agarwal A, Deore RB, Rudagi $K$, Nanda Z, Baig MO, Fareez MA. Evaluation of Apical Vapor Lock Formation and comparative Evaluation of its Elimination using Three different Techniques: An in vitro Study. J Contemp Dent Pract 2017;18(9):790-794.

Source of support: Nil

Conflict of interest: None

\section{INTRODUCTION}

Complete debridement of the canal system is a primary requirement for the long-term success of root canal treatment. ${ }^{1-4}$ According to Walton and Torabinejad, ${ }^{5}$ the important factor is the irrigation delivery system than the irrigating solution per se. The debridement efficacy of an irrigation delivery / agitation system depends on how well the irrigant reaches the apical region, the uninstrumented zones, and creates a strong enough current to carry the debris out of the root canal coronally. ${ }^{6-10}$ Positive-pressure irrigation is the most common method of introducing the irrigant in the root canals. Negative-pressure irrigation has been introduced in 2004 recently with promising results for apical irrigation. Application of ultrasonic and sonic oscillations and MDA with a K-file or a well-fitted gutta-percha cone provides agitation of the irrigant. ${ }^{11}$

During the cleaning and shaping, as the root is surrounded by the bone socket, ${ }^{12-14}$ it acts as a closed-ended channel, causing gas entrapment at its closed end during irrigant delivery, ${ }^{15-17}$ producing a vapor lock effect. ${ }^{18,19}$

Studies conducted on apical vapor lock without ensuring a closed-ended channel at the apical end cannot be 
regarded as conclusive. The research study was taken up for the three irrigation techniques in terms of evaluating the formation and elimination of the apical vapor lock, which is a very important concept in irrigation in endodontics.

\section{MATERIALS AND METHODS}

\section{Experimental Design}

A total of 60 extracted human single-rooted lower premolars were radiographed to ensure that each tooth contained one canal, such that an equal number of narrow (25\%) and wide canals (75\%) was present in the three experimental groups. To create a closed canal system, the cementum of each root was coated with tray adhesive. The root tip was coated with flexible, hot glue which was allowed to solidify, and the tooth was inserted in a wax block.

Each tooth was decoronated at $17 \mathrm{~mm}$ from the anatomic apex. Patency of the canal was achieved with a no. 10 K-file (Mani, Japan). Working length was established at $1 \mathrm{~mm}$ short of the apical foramen. Each canal was filled with $3 \% \mathrm{NaOCl}$ as an irrigant during instrumentation. Each root was instrumented to size F4 Protaper (DENTSPLY, Tulsa Dental Specialties); 3\% NaOCl (Asian, India) was delivered with a $30-G$ needle which was placed $1 \mathrm{~mm}$ short of the working length; $1 \mathrm{~mL}$ of $3 \% \mathrm{NaOCl}$ was used to irrigate the canal between each instrument.

Ethylenediaminetetraacetic acid (EDTA) liquid (Dent Wash, Prime Dental Products, India) 17\% was used as the final irrigant to remove the smear layer; $5 \mathrm{~mL}$ of $17 \%$ EDTA liquid was delivered with the $30-\mathrm{G}$ needle and left in the canal for 5 minutes. Irrigants were delivered at the rate of $5 \mathrm{~mL} /$ minute. Each canal was subsequently irrigated with $5 \mathrm{~mL}$ of deionized water and dried with paper points.
All the teeth were then irrigated with a contrasting media $8 \mathrm{M}$ cesium chloride $+3 \%$ sodium hypochlorite mix in equal proportions, delivered through the $30-\mathrm{G}$ needle $1 \mathrm{~mm}$ short of the working length. The needle was removed and the teeth were placed under Sirona CBCT scanner and snapshots obtained of the formed apical vapor lock (Fig. 1).

The formation of vapor lock was verified in the CBCT scanner (Fig. 1), and all the teeth were divided randomly into three groups of 20 teeth each and subjected to the three techniques. In group I, EndoActivator (DENTSPLY Tulsa Dental Specialties) was used at a frequency of 6000 $\mathrm{Hz}$ (medium frequency) using \#15 2\% polymer tip $1 \mathrm{~mm}$ short of the working length for 1 minute for the teeth specimen.

In group II, passive ultrasonic irrigation (Irrisafe; Satelec, Acteon equipment) was performed for 1 minute at medium power setting with a \#15 ultrasonic file at $1 \mathrm{~mm}$ short of the working length.

In group III, MDA was performed using a No. $15 \mathrm{~K}$-file (Mani, Japan) $1 \mathrm{~mm}$ short of working length and agitated in and out 2 to $3 \mathrm{~mm}$ for 1 minute. All the samples were again placed under the Sirona CBCT scanner and snapshots obtained (Fig. 2).

\section{Statistical Analysis}

The data were analyzed using Chi-square test. The statistical significance was set at $\mathrm{p} \leq 0.05$. The statistical analyses were performed using Statistical Package for the Social Sciences version 15.0 software.

\section{RESULTS}

Apical vapor lock was formed in all the samples (Fig. 1). Out of the 20 teeth in each group, the apical vapor lock was eliminated in 18 samples of EndoActivator (group I),
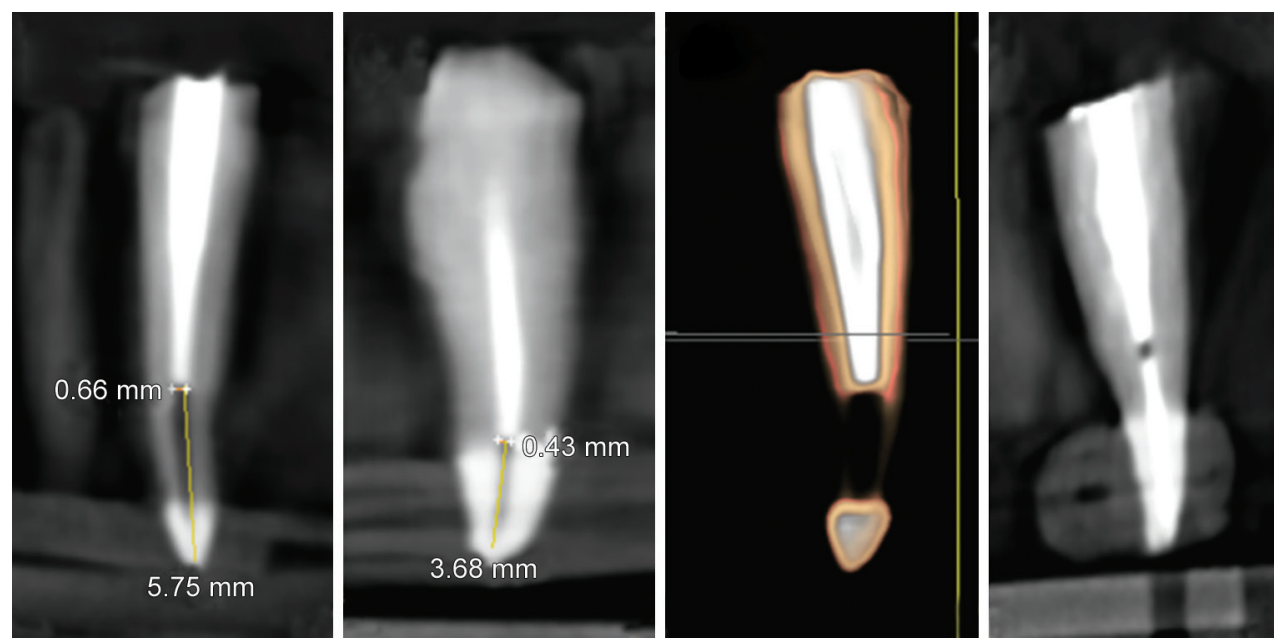

Fig. 1: СBCT snapshots of vapor lock formation 

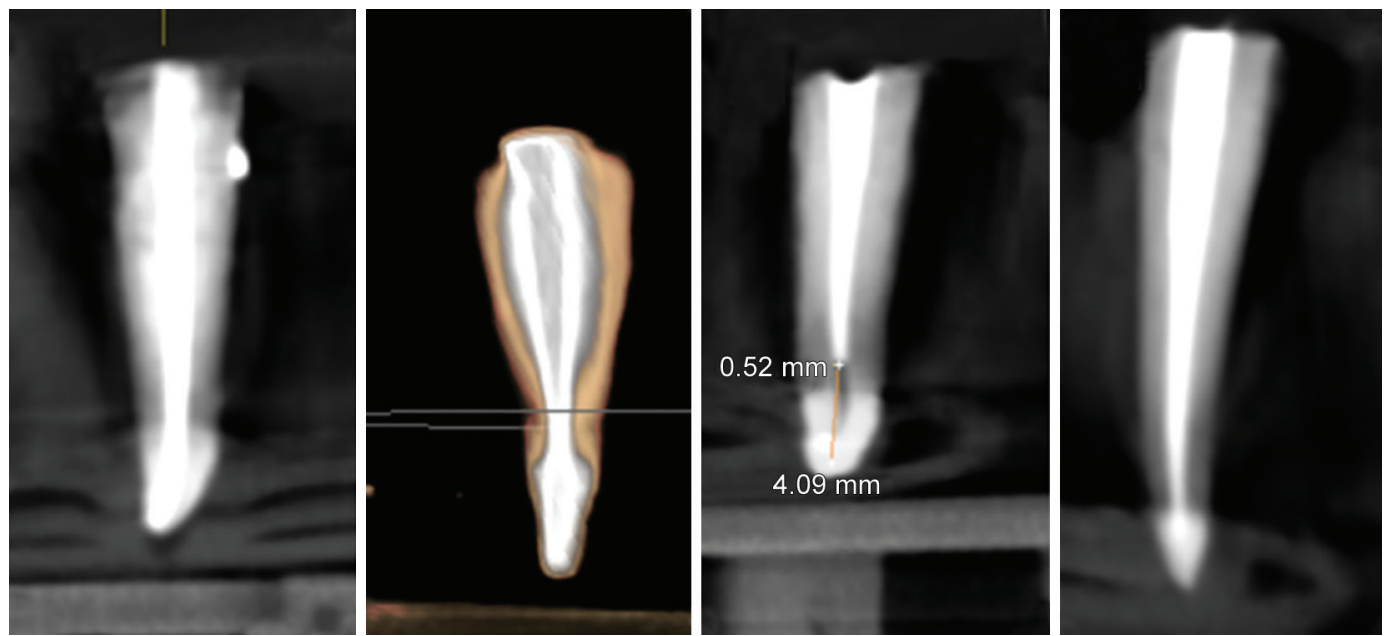

Fig. 2: $\mathrm{CBCT}$ images after use of three techniques (postoperative)

Table 1: Distribution of apical vapor lock formation across study groups

\begin{tabular}{lll}
\hline Groups & $\begin{array}{l}\text { Vapor locks } \\
\text { eliminated, } n(\%)\end{array}$ & $\begin{array}{l}\text { Vapor locks not } \\
\text { eliminated, } n(\%)\end{array}$ \\
\hline EndoActivator & $18(90)$ & $2(10)$ \\
Ultrasonics & $16(80)$ & $4(20)$ \\
Manual agitation & $10(50)$ & $10(50)$ \\
\hline
\end{tabular}

16 samples of ultrasonics (group II), while it was eliminated in 10 samples by MDA (group III; Tables 1 and 2).

\section{DISCUSSION}

The area of focus in the present study was the irrigation of the apical third of root canal system as the importance of apical one-third irrigation is multifold. In closed systems, especially in the apical $1 \mathrm{~mm}$ of the root, there is significantly more smear layer and debris remaining. ${ }^{20}$ This is explained by the formation of an apical vapor lock, which occurs when there is gas entrapment in the apical region of the canal. This has been described as the difficulty of dispersion and mixing of an irrigant in a confined space, whereas in an open canal system, this would not occur, and the irrigant would flow out of the apical foramen. ${ }^{21}$

Following balanced force instrumentation technique in oval canals of lower incisors, uninstrumented regions can be present in up to $65 \%$ of teeth, whereas 65 to $74 \%$ of the apical $4 \mathrm{~mm}$ of distal roots of lower molars remain untouched after shaping by rotary files. ${ }^{22}$ This implies that the bulk of debridement and cleaning in the apical third of root canal system has to be carried out by irrigation.

The studies applying engineering and physics, such as analytical modeling, computational fluid dynamics, and scaled laboratory experiments have confirmed the presence of a stagnation plane, beyond which root canal irrigant will not penetrate from the tip of the needle. ${ }^{21}$ Greater the distance between this plane from the tip of the needle, better would be the penetration of the irrigant.
Table 2: Comparison of vapor lock elimination among groups

\begin{tabular}{lll}
\hline Groups & Chi-square value & $p$-value \\
\hline EndoActivator vs ultrasonics & 8.889 & $0.032^{*}$ \\
EndoActivator vs manual agitation & 5.000 & $0.045^{*}$ \\
Ultrasonics vs manual agitation & 5.012 & $0.043^{*}$ \\
\hline
\end{tabular}

Chi-square test; *significant at $p<0.05$

During irrigation, one would desire ideally the stagnation plane to coincide with the working length.

Root canal morphology studies have shown that the canals are seldom straight or conical. The root canals have lateral canals, transverse anastomoses, webs, fins, and apical deltas, which are variations in canal morphology frequently encountered. This further complicates the apical third debridement and highlights its importance. ${ }^{23}$

In the current sample design, glue was used at the apical end of all the samples to simulate a closed root canal system. The closed canal system was chosen in the present study owing to them being the majority of the routine cases for endodontic therapy, whereas cases with a sinus tract represent an example of an open root canal system.

The present study evaluated the formation of apical vapor lock and compared the three irrigation activation techniques (ultrasonic activation, sonic activation, and MDA) in terms of eliminating the vapor lock.

The vapor lock was formed in all the samples on conventional syringe irrigation. This can be attributed to the fact that the root canal is a closed canal system in a confined space of continuously tapering cone, and experiments in physics demonstrate gas entrapment during fluid introduction in such narrow spaces. ${ }^{23}$

In ultrasonics, the energy is transmitted by means of ultrasonic waves and activates the flow of irrigant by acoustic microstreaming and cavitation. Cavitation occurs at the ultrasonic file tip, whereas acoustic microstreaming occurs at the sides of the ultrasonically activated file. ${ }^{13,24-26}$ 
Sonic irrigation differs from ultrasonic irrigation in that the frequencies range from 1 to $6 \mathrm{kHz}$, which is lower as compared with ultrasonics $(25-44 \mathrm{kHz}){ }^{27}$ In this study, the ultrasonically activated file was effective in eliminating the vapor lock but less effective than the EndoActivator, i.e., sonic system. The reason for this might be the fact that the numerous negative and positive nodes along the length of an ultrasonic file undesirably dampen the amplitude when the file touches the root canal walls. In contrast, sonic activation works at only one single negative and positive node, and the movement caused by the vibratory polymer tip did not change by contact laterally with the root canal walls. ${ }^{28}$

Meanwhile, during MDA, it is possible that the air bubble in the apical region is eliminated during manual K-file insertion, but the air entrapment reoccurs during removal of the K-file; hence, MDA can result in more debris in the apical regions of the root canal. ${ }^{29}$

Our results are in agreement with the previous study by de Gregorio et al, ${ }_{19}^{19}$ using ultrasonic and sonic (EndoActivator) activations in lateral canals, wherein they found irrigation in the apical third (at 4.5 and $2 \mathrm{~mm}$ from working length) better than that with traditional needle irrigation alone. The results of our study are in contrast to a previous study by Klyn et $\mathrm{al}_{,}{ }^{26}$ wherein they found no statistically significant difference for canal cleanliness between ultrasonic and sonic groups. The results of the present study are in contrast to a study by Jiang et $\mathrm{al}^{30}$ wherein they found that the ultrasonic activation was significantly more efficient than sonic activation.

Further studies incorporating both open and closed designs for the ability of these techniques to eliminate the vapor lock have to be validated. Future research is warranted to assess the effect of ultrasonic, EndoVac, and sonic activation of irrigants on disinfection, debridement, and removal of smear layer from the apical third of root canals.

\section{CONCLUSION}

Within limitations of this study, it is concluded that

- Apical vapor lock is consistently formed during endodontic irrigation in closed canal systems

- Sonic activation performs better than the ultrasonics and MDA in eliminating the apical vapor lock, with statistically significant differences between all three groups.

\section{CLINICAL SIGNIFICANCE}

Results of the present study suggest that the apical vapor lock (dead water zone) is consistently formed during routine endodontic irrigation which impedes irrigant penetration till the working length, thereby leading to inefficient debridement. Hence, to eliminate this vapor lock, techniques, such as sonics or ultrasonics should be used along with the irrigant after cleaning and shaping of the root canal.

\section{REFERENCES}

1. Schilder H. Cleaning and shaping the root canal. Dent Clin North Am 1974 Apr;18(2):269-296.

2. Sjögren U, Figdor D, Persson S, Sundqvist G. Influence of infection at the time of root filling on the outcome of endodontic treatment of teeth with apical periodontitis. Int Endod J 1997 Sep;30(5):297-306.

3. Nair PN. Pathogenesis of apical periodontitis and the causes of endodontic failures. Crit Rev Oral Biol Med 2004 Nov;15(6):348-381.

4. Haapasalo M, Endal U, Zandi H, Coil JM. Eradication of endodontic infection by instrumentation and irrigation solutions. Endod Top 2005 Mar;10(1):77-102.

5. Walton, R. E., \& Torabinejad, M. (2002). Principles and practice of endodontics. Philadelphia, PA: Saunders

6. Moser JB, Heuer MA. Forces and efficacy in endodontic irrigation systems. Oral Surg Oral Med Oral Pathol 1982 Apr;53(4):425-428.

7. Chow TW. Mechanical effectiveness of root canal irrigation. J Endod 1983 Nov;9(11):475-479.

8. Sedgley CM, Nagel AC, Hall D, Applegate B. Influence of irrigant needle depth in removing bioluminescent bacteria inoculated into instrumented root canals using real-time imaging in vitro. Int Endod J 2005 Feb;38(2):97-104.

9. Boutsioukis C, Lambrianidis T, Kastrinakis E. Irrigant flow within a prepared root canal using various flow rates: a computational fluid dynamics study. Int Endod J 2009 Feb;42(2):144-155.

10. Gao Y, Haapasalo M, Shen Y, Wu H, Li B, Ruse ND, Zhou X. Development and validation of a three-dimensional computational fluid dynamics model of root canal irrigation. J Endod 2009 Sep;35(9):1282-1287.

11. Fukumoto Y, Kikuchi I, Yoshioka T, Kobayashi C, Suda H. An ex vivo evaluation of a new root canal irrigation technique with intracanal aspiration. Int Endod J 2006 Feb;39(2):93-99.

12. Usman N, Baumgartner JC, Marshall JG. Influence of instrument size on root canal debridement. J Endod 2004 Feb;30(2):110-112.

13. Gutarts R, Nusstein J, Reader A, Beck M. In vivo debridement efficacy of ultrasonic irrigation following hand-rotary instrumentation in human mandibular molars. J Endod 2005 Mar;31(3):166-170.

14. Burleson A, Nusstein J, Reader A, Beck M. The in vivo evaluation of hand/rotary/ultrasound instrumentation in necrotic, human mandibular molars. J Endod 2007 Jul;33(7):782-787.

15. Dovgyallo GI, Migun NP, Prokhorenko PP. The complete filling of dead-end conical capillaries with liquid. J Eng Phys 1989 Apr;56(4):395-397.

16. Migun NP, Azuni MA. Filling of one-side-closed capillaries immersed in liquids. J Colloid Interface Sci 1996 Jul;181(1):337-340.

17. Pesse AV, Warrier GR, Dhir VK. An experimental study of the gas entrapment process in closed-end microchannels. Int J Heat Mass Transfer 2005 Dec;48(25-26):5150-5165.

18. Senia ES, Marshall FJ, Rosen S. The solvent action of sodium hypochlorite on pulp tissue of extracted teeth. Oral Surg Oral Med Oral Pathol 1971 Jan;31(1):96-103. 
19. de Gregorio C, Estevez R, Cisneros R, Heilborn C, Cohenca N. Effect of EDTA, sonic, and ultrasonic activation on the penetration of sodium hypochlorite into simulated lateral canals: an in vitro study. J Endod 2009 Jun;35(6): 891-895.

20. Tay FR, Gu LS, Schoeffel GJ, Wimmer C, Susin L, Zhang K, Arun SN, Kim J, Looney SW, Pashley DH. Effect of vapor lock on root canal debridement by using a side-vented needle for positive-pressure irrigant delivery. J Endod 2010 Apr;36(4):745-750.

21. Gulabivala K, Ng YL, Gilbertson M, Eames I. The fluid mechanics of root canal irrigation. Physiol Meas 2010 Dec;31(12):R49-R84.

22. Wu MK, Wesselink PR. A primary observation on the preparation and obturation of oval canals. Int Endod J 2001 Mar;34(2):137-141.

23. Ricucci D, Siqueira JF Jr. Fate of the tissue in lateral canals and apical ramifications in response to pathologic conditions and treatment procedures. J Endod 2010 Jan;36(1):1-15.

24. Lee SJ, Wu MK, Wesselink PR. The effectiveness of syringe irrigation and ultrasonics to remove debris from simulated irregularities within prepared root canal walls. Int Endod J 2004 Oct;37(10):672-678.
25. Goodman A, Reader A, Beck M, Melfi R, Meyers W. An in vitro comparison of the efficacy of the step-back technique versus a step-back/ultrasonic technique in human mandibular molars. J Endod 1985 Jun;11(6):249-256.

26. Klyn SL, Kirkpatrick TC, Rutledge RE. In vitro comparisons of debris removal of the EndoActivator system, the F file, ultrasonic irrigation, and $\mathrm{NaOCl}$ irrigation alone after handrotary instrumentation in human mandibular molars. J Endod 2010 Aug;36(8):1367-1371.

27. Ahmad M, Pitt Ford TJ, Crum LA. Ultrasonic debridement of root canals: acoustic streaming and its possible role. J Endod 1987 Oct;13(10):490-499.

28. van der Sluis LW, Versluis M, Wu MK, Wesselink PR. Passive ultrasonic irrigation of the root canal: a review of the literature. Int Endod J 2007 Jun;40(6):415-426.

29. Parente JM, Loushine RJ, Susin L, Gu L, Looney SW, Weller RN, Pashley DH, Tay FR. Root canal debridement using manual dynamic agitation or the EndoVac for final irrigation in a closed system and an open system. Int Endod J 2010 Nov;43(11):1001-1012.

30. Jiang LM, Verhaagen B, Versluis $M$, van der Sluis LW. Evaluation of a sonic device designed to activate irrigant in the root canal. J Endod 2010 Jan;36(1):143-146. 